\title{
Emergence of Non-albicans Candida in urine of diabetic patients at Gwalior (M.P.), India
}

\author{
Dr. Manish Pandey ${ }^{1}$, Dr. Amita Pandey ${ }^{2}$ \\ ${ }^{1}$ (Departmentof micobiology, IASCA, ITM Universe, Gwalior, India) \\ ${ }^{2}$ (Department of Microbiology, Govt. SMS Model Science College, Gwalior,India)
}

\begin{abstract}
The frequent occurrence of Candida infections in patients with diabetes mellitus has been recognized for many years and is thought to be more prevalent among these individuals. The objective of the study was to focus on the isolation of non-albicans Candida in urine of diabetic patients. A total of 80 samples in urine of diabetic patients treated in hospitals, clinics and nursing homes and from pathological laboratories at Gwalior (M.P.), India were recruited for the study. Among the diabetic patients $62.5 \%$ (50/80) had Candida infections. The major Candida species isolated were Candida tropicalis 34\% (17) followed by C. albicans 30\% (15), C. parapsilosis $16 \%(08)$, C. glabrata $14 \%(07)$ and C. krusei $6 \%(03)$. This study indicates that non- albicans Candida are also emerging in urine of diabetic patients.
\end{abstract}

Keywords - non-albicans Candida, Diabetes mellitus, urine, infections, Patients

\section{INTRODUCTION}

Diabetes mellitus is a common and growing global health problem which causes several complications [1]. Candida species are commensal micro-organisms that become pathogenic when the defence mechanisms of the host are weakened, and these organisms then have the ability to cause a variety of superficial and systemic infections [2; 3]. Experimental studies have shown that the growth of the Candida species has particularly favorable conditions in the urinary tract. Due to a high urine glucose concentration, patients with diabetes show increased susceptibility to fungal infections in the urinary tract $[4 ; 5]$.

There are over 150 fungi from the Candida species which are present in our environment as saprophytes. Merely a few of those are pathogenic for man [6,5]. Although $C$. albicans is the organism most often associated with serious fungal infection, other Candida species also have emerged as clinically important opportunistic pathogen [7] and those most frequently isolated are: $C$. tropicalis, $C$ krusei, $C$. parapsilosis, $C$. stellatoidea, C. glabrata and the primarily amphotericin B-resistant $C$. lusitanie.

The present study was undertaken with a view to see the occurrence of the most prevalent fungi causing candiduria in diabetic patients and were identified \& allocated to a species. The aim was to assess the prevalence of non-albicans Candida in diabetic patients.

\subsection{Sample collection}

\section{Methodology}

A total of 80 urine samples were collected from diabetic patients being treated in hospitals, clinics and nursing homes and from pathological laboratories at Gwalior (M.P.), India. The urine was collected in a sterile, dry, wide-necked, leak-proof container. Commonest age group was between 36-45 years \& male patients predominate in all age groups. The samples were identified on the basis of cultural, microscopical, biochemical tests and special tests like Chlamydospores formation and germ tube test were performed using various manuals [8;9]. The sugar fermentation and assimilation tests were taken as the gold standard for differentiation of Candida species.

\subsection{Colony characters}

For candidal isolation, samples were inoculated on Sabouraud's dextrose agar plates to which streptomycin was added to inhibit bacterial growth. The plates were incubated at $37^{\circ} \mathrm{C}$ for 48 hours after which the colonies were studied for their morphological characters such as: colony appearance, colony colour, colony shape, colony texture, and production of hyphae and pseudo hyphae.

\subsection{Germ tube production}

A small amount of yeast was suspended in individual tubes containing serum. The test tubes were incubated at $37^{\circ} \mathrm{C}$ for 2 to 3 hours. One drop of each yeast-serum suspension was placed on a glass slide along with India ink, to be observed as a wet preparation. Under the microscope each slide was examined for the presence of germ tubes. 


\subsection{Chlamydospore production}

Each Candida isolates were picked up with a straight wire and was streaked through deep cutting on corn meal agar plate at an angle and was then covered with a sterile cover slip to produce a relative anaerobic condition. The plates were incubated at $25^{\circ} \mathrm{C}$ for 3 days. At every 24 hours interval the plates were examined under microscope for the presence of chlamydospores.

\subsection{Urease Test}

Christensen's urea broth indicates the presence of the enzyme urease, which splits urea into ammonia, resulting in an alkaline environment. The phenol red indicator turns the media from a straw yellow to fuschia at $\mathrm{pH} 8.4$.

\subsection{Sugar Fermentation and Assimilation}

Diluted suspension of pure $48 \mathrm{hrs}$ old yeast culture was prepared in distilled water equal to a no. $1 \mathrm{Mc}$ Farland. Now a single drop of this suspension was added to each tube of yeast fermentation broth. A layer of molten Vasper was added directly on to the top of the broth. All the tubes were finally incubated at 25 to $30^{\circ} \mathrm{C}$ and shaken daily. Reading was taken every 2 to 3 days for the first week and then weekly up to 24 days. All the tubes were observed for turbidity and presence of the gas in the invert Durham tube in the case of sugar fermentation. Sugar assimilation was examined by the colour change of broth from blue to yellow in the presence of $\mathrm{pH}$ indicator bromothymol blue. Outcome criteria for sugar fermentation and assimilation are shown in Table I \& II.

TABLE I SUGAR FERMENTATION

\begin{tabular}{|l|l|c|c|c|c|c|}
\hline \multirow{2}{*}{ S.N. } & \multirow{2}{*}{ Sugar } & \multicolumn{5}{|c|}{ Species } \\
\cline { 3 - 7 } & & C. albicans & C.tropicalis & C. parapsilosis & C. glabrata & C. krusei \\
\hline 1. & Glucose & + & + & + & + & + \\
\hline 2. & Maltose & + & + & - & - & - \\
\hline 3. & Sucrose & - & + & - & - & - \\
\hline 4. & Lactose & - & - & - & - & - \\
\hline 5. & Galactose & + & + & - & + & - \\
\hline 6. & Trehalose & + & + & - & + & - \\
\hline
\end{tabular}

TABLE II SUGAR ASSIMILATION

\begin{tabular}{|c|c|c|c|c|c|c|}
\hline \multirow[t]{2}{*}{ S.N. } & \multirow[t]{2}{*}{ Sugar } & \multicolumn{5}{|c|}{ Species } \\
\hline & & C. albicans & C. tropicalis & C. parapsilosis & C. glabrata & C. krusei \\
\hline 1. & Glucose & + & + & + & + & + \\
\hline 2. & Maltose & + & + & + & + & - \\
\hline 3. & Sucrose & + & + & + & - & - \\
\hline 4. & Lactose & - & - & - & - & - \\
\hline 5. & Galactose & + & + & + & - & - \\
\hline 6. & Melibiose & - & - & - & - & - \\
\hline 7. & Cellobiose & - & + & - & - & - \\
\hline 8. & Inositol & - & - & - & - & - \\
\hline 9. & Xylose & + & + & + & - & - \\
\hline 10. & Raffinose & - & - & - & - & - \\
\hline 11. & Trehalose & + & + & + & + & - \\
\hline 12. & Dulcitol & - & - & - & - & - \\
\hline
\end{tabular}

III. RESULT

Out of 80 samples, 50 samples were positive from male (32) and female (18). The greatest incidence was found in the age group of 56 to 65 years in male patients (10) and 36 to 45 years in female patients (12) as shown in Table III

TABLE III AGE AND SEX INCIDENCE OF PATIENTS

\begin{tabular}{|c|l|l|l|l|}
\hline & \multicolumn{2}{|c|}{ Male } & \multicolumn{2}{c|}{ Female } \\
\hline Age (Years) & Sample & +ve & Sample & + ve \\
\hline$<22$ & 01 & - & - & - \\
\hline
\end{tabular}


Emergence of Non-albicans Candida in urine of diabetic patients at Gwalior (M.P.), India

\begin{tabular}{|c|l|l|l|l|}
\hline $25-35$ & 05 & 03 & 04 & 02 \\
\hline $36-45$ & 13 & 08 & 17 & 12 \\
\hline $46-55$ & 09 & 05 & 03 & 02 \\
\hline $56-65$ & 13 & 10 & 03 & 01 \\
\hline $66-75$ & 04 & 02 & 03 & 01 \\
\hline $76-85$ & 05 & 04 & - & - \\
\hline Total & 50 & 32 & 30 & 18 \\
\hline
\end{tabular}

Out of total samples, Candida tropicalis was more frequently isolated from 17 cases (34\%) cases followed by C. albicans 15 (30\%), C. parapsilosis 08 (16\%), C. glabrata 07 (14\%) and Candida krusei 03 (6\%) was the least isolate from diabetic patients.

TABLE IV NO. OF Candida ISOLATES

\begin{tabular}{|l|l|}
\hline Candida Spp. & No. of Isolates \\
\hline C. albicans & $15(30 \%)$ \\
\hline Non albicans Candida \\
\hline C. tropicalis & $17(34 \%)$ \\
\hline C. parapsilosis & $08(16 \%)$ \\
\hline C. glabrata & $07(14 \%)$ \\
\hline C. krusei & $036 \%)$ \\
\hline
\end{tabular}

\section{Discussion}

Clinical observations indicate that patients with diabetes, belong to the group of increased risk of mycotic infections. C. albicans is generally considered as the major pathogenic among the Candida spp. Although an increase in the prevalence of non-albicans spp. has been noted during the past decade, because of the extensive use of antimycotic drugs particularly azoles, for prolonged periods. Therapeutic courses has led to changes in the relative prevalence of various Candida spp. with a decrease in the proportion of C. albicans as the etiological agent of candidiasis and an increase in the proportion of non albicans spp. such as C. glabrata and C. krusei $[10 ; 11]$

'The prevalence of candiduria caused by the species other than C. albicans was surprisingly high. In fact, non albicans Candida accounted for $70 \%$ of all Candida isolates.Earlier, it was considered that $C$. albicans was the only species causing infection and $C$. parapsilosis, $C$. tropicalis and $C$. guilliermondii were considered only as occasional pathogens $[12 ; 13]$. However $C$. albicans was dominated but in our study this was cleared that non-albicans Candida spp. were also frequently isolated from diabetic patients.

Our study revealed that out of 80 urine samples of diabetic patients, $50(64.5 \%)$ samples were positive for the presence of Candida spp. Out of them 35 (64\%) were male and 18 (36\%) female. C. albicans isolated from 15 samples (30\%) whereas C. tropicalis, C. parapsilosis, C. glabrata and C. krusei reported from 17 (34\%), $8(16 \%), 7(14 \%)$ and $3(6 \%)$ cases respectively.

C. krusei causes infection mainly in critically ill patients and is most often isolated in hematology patients with severe neutropenia. It is an uncommon pathogen causing candidemia [13]. But our results showed that $C$. krusei was also isolated from urine (6\%). In the present study non-albicans Candida spp. (55.8\%) were isolated at a higher rate than C. albicans.

\section{CONCLUSION}

The conclusion emerged from this study indicates that non- albicans Candida are also emerging in urine of diabetic patients. Isolation rate of all the Candida spp. have been observed to be much higher in this study and it can be concluded that the need for mycological evaluation of urine samples of diabetic patients and appropriate antifungal therapy.

\section{REFERENCES}

[1] Mohammad Hossein Lotfi-Kamran, Abbas Ali Jafari, Abbas Falah-Tafti*, Ehsan Tavakoli, Mohammad Hossein Falahzadeh, Candida Colonization on Denture of Diabetic, Dent Res J, 6 (1), 2009, 23-27.

[2] E. M. Kojic and R. O. Darouiche, Candida infections of medical devices, Clin Microbiol Rev, 17, 2004, $255-267$.

[3] S. Silva, M. Negri, M. Henriques, R. Oliveira, D. Williams and J. Azeredo, Silicone colonization by non-Candida albicans Candida species in the presence of urine, J Med Microbiol, 59, 2010, 7 747-754.

[4] G.P. Bodey, V. Fainstein, Candidiasis ( New York Raven Press,1985).

[5] A. Szypowska, Fungal infections in diabetes, () Borgis - New Medicine 1/2001, 12-15.

[6] JA Vazquez, JD Sobel, Fungal infection in diabetes, Infect Dis Clin North Am, 9 (1), 1995, 97-116.

[7] M Vinitha and M Ballal, Distribution of Candida Species in different clinical samples and their virulence: Biofilm formation, proteinase and phospholipase production: A study on hospitalized patients in Southern India, Journal of Global Infectious Diseases, 3 (1), 2011, 4-8.

[8] KJ Kwon-Chung. and J.E.Bennett, Medical mycology ( Second edition Lea \& Febiger, 1992, 280-326). 
[9] N. F. Conant, et al., Manual of clinical mycology $2^{\text {nd }}$ Ed. W.B. Saunders Co., 1954, New York).

[10] J. Chander, A Text Book of Medical Mycology, (2 $2^{\text {nd }}$ edition Publishers Interprint, 1998, 21: 134).

[11] A. Usharani, M. Bharathi, C. Sandhya, Isolation And Characterisation Of Candida Species From Oropharyngeal Secretions Of Hiv Positive Individuals, N Dermatol Online, 2011, 2(3), 119-124.

[12] G.P. Moran, D.J. Sullivan, D.C. Coleman, Emergence of non-Candida albicans Candida species as pathogens. In: Calderone RA. Candida and Candidiasis (ASM Press, Washington, 4th Edition, 2002, 4, 37-53.

[13] J.H. Meurman,. Siikala1, M. Richardson and R. Rautema, Non-Candida albicans Candida yeasts of the oral cavity, Communicating Current Research and Educational Topics and Trends in Applied Microbiology, A. Me'ndez Vilas (Ed.), OFORMATEX 2007 